\title{
Challenges of Teaching English Language in a Multilingual Setting: An Investigation at Government Girls Secondary Schools of Quetta, Baluchistan, Pakistan
}

\author{
Shumaila Rasheed ${ }^{1}$, Muhammad Zeeshan ${ }^{1} \&$ Najia Asrar Zaidi ${ }^{1}$ \\ ${ }^{1}$ Institute of English Language \& Literature, University of Baluchistan, Quetta, Pakistan \\ Correspondence: Shumaila Rasheed, Institute of English Language \& Literature, University of Quetta, \\ Baluchistan, Pakistan. Tel: 92-335-2325-688. E-mail: shumaila_abdullah914@yahoo.com
}

Received: March 27, 2017 Accepted: April 24, 2017 Online Published: July 15, 2017

doi:10.5539/ijel.v7n4p149 URL: http://doi.org/10.5539/ijel.v7n4p149

\begin{abstract}
Baluchistan is a multi-linguistic and multi-ethnic province of Pakistan. In this region, the inhabitants for communication purpose speak a number of local languages such as Baluchi, Brahvi, Pashto, Saraiki, Punjabi, Urdu, Sindhi and Persian. Students who attend the government schools speak these languages. This study aimed to explore the challenges faced by the secondary school female teachers while teaching the English language in their multilingual classrooms. The purposive sampling was used and 10 government secondary school female teachers participated in the study. The data was collected through a semi-structured interview protocol and classroom observation checklist. The data was analyzed by using thematic analyses technique. The findings of the study revealed a number of challenges. Teaching English language in a multilingual context is an enormous challenge for the English teachers due to linguistic diversity in the classrooms. The students in the multilingual classrooms lack confidence to use English language because they hesitate to commit mistakes. The curriculum may be inappropriate for helping students to improve their English proficiency. In the multilingual classrooms code-switching is commonly used by the teachers to instruct the students. The study suggests that; the teachers may be trained to cope with the challenges they face in their multilingual classrooms.
\end{abstract}

Keywords: multilingual context, secondary level, teaching of English, challenges

\section{Introduction}

The growing need of the English language makes it even more important to learn. According to Paik (2008), English is perceived as an indispensable tool in order to live in the global economy; therefore, the demand for learning English language is speedily increasing. Despite the need and importance of English language, it has been observed in the context of Pakistan that, students who have strong command over the English language can easily seek admissions into renowned educational institutions. On the other hand, students who lack proficiency may not have the access to the well-reputed educational institutions. Moreover, in Pakistan English is the language of all competitive exams. Lacking proficiency in the English language disadvantages the students (Zeeshan, 2013). According to Jimenez \& Rose (2010), without any systematic effort, students in the process of learning English have no hope of acquiring the kinds and amounts of social, cultural, and academic capital that they need to move into higher education or some significant work.

Teaching has the major role in the acquisition of English language. According to Patil (2008), teaching English is not only transmitting knowledge to the students; instead, it is to enable them to read, to speak and to write with fluency. However, in Baluchistan the situation is not so different from the other rural areas of Pakistan due to linguistic diversity in the region. According to Economic survey of Pakistan (2015), Baluchistan is one of the fifth and considered the most under privileged province of Pakistan because of poverty, unawareness and lack of education.

In Baluchistan, a number of local languages are spoken such as Pashto, Baluchi, Brahvi, Persian, Punjabi, Urdu and Saraiki. This multiculturalism may pose many challenges especially for the English teachers teaching at government schools located in Baluchistan. A multi-lingual classroom has elements like regional language, the local language and learners' mother tongue (Malone, 2007). Previously, there has not been any study conducted to explore the challenges faced by the female teachers, teaching English language in the multilingual classrooms 
such as in Baluchistan. This is the very first time a study is designed to investigate the challenges faced by the English language teachers and also to explore the strategies the teachers employ to cope with the challenges in Quetta, Baluchistan, Pakistan. Unfortunately, school based teachers' development activities are also lacking in this context and teachers are not given a chance to attend any training based on English language teaching.

The study has implications for the English language teaching and learning in Quetta, Baluchistan, Pakistan. This study will help both the English language teachers and students regarding teaching and learning strategies, which can be used in the multilingual classrooms.

\section{Literature Review}

Multilingual classrooms are considered as the biggest challenge for the English language teachers and students not only in Quetta, Pakistan but also in other parts of the world. The teachers and the students face a number of problems due to different local languages spoken by the students in the classrooms. Multilingual classrooms are not easy to handle and sometimes it becomes very difficult for the English teachers to cope with the challenges. Khan \& Khan (2016) conducted a study to explore the challenges faced by the English language teachers and students in the multilingual setting of district Mianwali and district Bhakkar, Punjab Pakistan. The participants were college students and teachers. Results of the study revealed that college students find difficult to learn English language due to the untrained teachers, education policy, examination system and lengthy syllabus. Haukås (2016) analyzed in his research the problems of a multilingual classroom in Norway. Twelve teachers were selected for the study including 6 Spanish, 4 French and 2 Germans. The data was collected through focused group discussions. The collected data was transcribed and coded for themes and patterns. The findings of the study revealed that learning a third language is entirely different than learning a second language. Teachers claimed to use their students' linguistic knowledge of English and Norwegian language while teaching the third language. Likewise, Abongdia \& Foncha (2015) carried out a study to analyze the challenges faced by pre-service English teachers, teaching English in East London, South Africa. The participants of the study were 8 pre-service English teachers. The study was qualitative and it focused the problems faced by the student teachers while teaching English language. The study emphasized on learners' discipline, resources, classroom management, supervision and observations. The results of the study suggested that teaching practice prepares the student teachers for their classes; it further suggests that placing the student teachers at the end of the year at schools is not a good proposal because it is a critical time for both the students and teachers. The study recommended that universities should work hand in hand with schools to assure that teachers and students are supported by the institute. Tufail, Kanwal, \& BadarToor (2015) conducted a study in district Pakpatan, Punjab, Pakistan to investigate the challenges faced by the learners while learning English language. The participants were 60 teachers teaching English language at different public and private schools. The finding of the study suggested that there should be teachers hired from the universities to conduct workshops for the English language teachers teaching in schools. Lartec Belisario, Bendanillo, Binas-o, \& Cammagay (2014) figured out the strategies used by the teachers in a multilingual classroom in Baguio city, Philippines. The participants were 12 kindergartens and grade one teachers. The data was collected through a semi-structured interview protocol. The recorded interviews were transcribed and coded for themes and patterns. The findings of the study revealed that teachers are facing a lot of problems due to language diversity in the classroom. The study recommended that there should be trainings for the English teachers to teach in the multilingual classrooms in an effective and interesting manner. Ismaili (2015) in his study analyzed the ethnic conflict in Macedonia. The study was conducted in South East University which is the only university to provide an opportunity to the Albanian and Macedonian students to study in their mother-tongue or choose English as a medium of instruction. Since the teachers and the students both belong to different lingual and cultural background so it becomes challenging for the teachers to teach and the students to learn English language. The data were collected through a questionnaire and classroom observations and were analyzed using qualitative and quantitative methods. The findings of the study revealed that students had positive attitude towards the use of L1 in the class. During classroom observations, the students found frustrated if the instructions were given in English language only. The study suggested that L1 should be used along with English language in the multilingual classrooms. Gopang, Bhugio, Umrani, \& Lohar (2015) examined the foreign language learning anxiety in one of their studies conducted in a university at Lasbela, Baluchistan, Pakistan. 240 participants were randomly selected for this research including 214 males and 26 females. The data was collected through two questionnaires and was analyzed using ANOVA and SPSS. The results of the study showed that students feel hesitant to speak in English language because they are afraid of committing mistakes which is the biggest hindrance in learning English language. Dhillon \& Wanjiru (2013) focused in one of their studies on the challenges of teaching and learning English language in Kenya. The participants were 20 teachers and the data were collected through a questionnaire and 
semi-structured interview protocol. The results of the study illustrated a number of challenges in learning English language in the multilingual setting of Kenya. It was suggested that teachers need to be trained enough to teach English language in a multilingual setting. Similarly, Noom-Ura (2013) investigated in one of his studies the challenges of teaching and learning English in three provinces of Thailand. The participants of the study were 34 secondary school teachers. The data was collected through open-ended and closed-ended questionnaires and was analyzed by frequency distribution and percentage. The results of the study revealed that local organizations and higher education should improve the situation of English teaching in Thailand. The study recommended that there should be professional development trainings, workshops, seminars and study trips for both the teachers and students not only in Thailand but in other countries as well. Akram \& Qureshi (2012) determined the challenges faced by the English teachers and learners in one of their studies in district Vehari, Punjab, Pakistan. Punjabi is commonly spoken language in this region. There were 100 teachers including 45 females and 55 males who participated in this research from four different colleges of district Vehari. The data was collected through a questionnaire and was analyzed using SPSS. The findings of the study revealed that teaching and learning English language becomes more difficult due to its difficult pronunciation and vocabulary. The study suggested that English should commonly teach at school level since the very beginning to the students so they may feel comfortable while learning it. Teevno (2011) figured out the challenges faced by the secondary school English teachers and students in their classrooms. The study was conducted in NaushahroFeroz, Sindh, Pakistan. The participants of the study were 11 English language teachers, 6 English experts and 70 secondary school students. The data from the teachers and students was gathered by focused group discussions and a questionnaire and the experts were interviewed. The results of the study showed that there are no proper trainings of the English language teachers; the syllabus was difficult and not according to the needs of the learners. This is why the teaching and learning English both are badly affecting in this context.

Previous studies show that teaching English language in the multilingual setting is the biggest challenge of this era. The past studies suggest that English language teachers should be trained so they may teach English language in an interesting and effective manner.

\section{Research Questions}

This study is guided by the following research questions.

- What are the challenges faced by the female government secondary school English teachers teaching in their multilingual classrooms?

- What strategies the female government secondary school English teachers employ to overcome the challenges of multilingual classrooms?

\section{Methodology}

This study aimed to investigate the challenges faced by the female secondary school teachers, teaching English language in the multilingual classrooms. The study also explores the strategies the government secondary school female English teachers may employ to overcome the challenges in their multilingual classrooms.

\subsection{Participants}

Purposive sampling was employed and 10 female secondary school teachers were selected for the study. The teachers were quite experienced and their ages ranged from 27 to 45 .

Table 1. Academic, lingual and professional background of the teachers

\begin{tabular}{llll}
\hline Participants & Qualification & Experience & L1 \\
\hline P1 & MA, M.Ed & 13 years & Urdu \\
P2 & M.Phil & 04 years & Pashto \\
P3 & BA, B.Ed & 07 years & Persian \\
P4 & MA, M.Ed & 11 years & Saraiki \\
P5 & M.A, M.Ed & 27 years & Punjabi \\
P6 & M.Phil & 08 years & Punjabi \\
P7 & M.Phil & 16 years & Pashto \\
P8 & M.A, M.Ed & 05 years & Urdu \\
P9 & BA, B.Ed & 04 years & Brahvi \\
P10 & M.A, M.Ed & 09 years & Baluchi \\
\hline
\end{tabular}


The educational qualification of the female teachers, teaching English at secondary schools of Quetta ranged from Bachelor of Arts (BA) to Masters of Arts (MA) with either Bachelor of Education (B.Ed) or Masters of Education (M.Ed) qualifications. Three of the teachers were M.Phil in Education. In an answer to the question that, how do they improve their teaching; teachers said that by self-study or available resources. The female teachers belonged to different lingual backgrounds such as, Punjabi, Pashto, Urdu, Brahvi, Persian, Saraiki and Baluchi.

\subsection{Instrument}

A semi-structured interview protocol (Appendix A) and classroom observation checklist (Appendix B) was used to collect the data. Cohen et al. (2007) regarded interviews as a valuable method to explore the construction and negotiation of meanings in a natural setting. However, interviews are considered more powerful in eliciting narrative data that allows the researcher to investigate people views in depth. Two to three lessons of each research participant were observed and followed by the interview. Teachers were asked the questions regarding pedagogical techniques used in the class, medium of instructions used by the teachers and about different class activities regarding English language teaching.

Interviews were transcribed and coded. The data was constantly arranged and analyzed to find patterns and themes by using thematic analysis technique.

\subsection{Data Analysis}

The interview protocol (Appendix A) was consisted of questions like background information of the participants, their mother-tongue and challenges they were facing in their multilingual classrooms. Furthermore, the class of each participant was observed by following an observational checklist (Appendix B). The interviews were transcribed, coded and reviewed for major themes through thematic analysis technique. Braun \& Clarke (2006) says that, "thematic analysis is a method used for identifying, analyzing and reporting patterns (themes) within the data" (p. 97).

\section{Findings of the First Research Question}

As emerged from data analysis, the results are discussed under the theme of multilingual class, students' weak linguistic background, lengthy syllabus, anxiety factor among learners and lack of teacher trainings.

Table 2. Challenges faced by the secondary school teachers in their multilingual classrooms

\begin{tabular}{|c|c|c|c|}
\hline Themes & Sub-Themes & Frequency & Percentage \\
\hline \multirow[t]{2}{*}{ Multilingualism } & Students belong to different lingual backgrounds. & 06 & $60 \%$ \\
\hline & Class is multilingual. & 04 & $40 \%$ \\
\hline Total & & 10 & $100 \%$ \\
\hline \multirow{3}{*}{$\begin{array}{l}\text { Weak Linguistic Background } \\
\text { of the Learners. }\end{array}$} & Students cannot understand English language. & 06 & $60 \%$ \\
\hline & No exposure towards English language. & 03 & $30 \%$ \\
\hline & Linguistic background does not matter & 01 & $10 \%$ \\
\hline Total & & 10 & $100 \%$ \\
\hline \multirow[t]{3}{*}{ Anxiety among Learners } & Students feel shy. & 06 & $60 \%$ \\
\hline & They lack confidence. & 03 & $30 \%$ \\
\hline & Anxiety does not matter & 01 & $10 \%$ \\
\hline Total & & 10 & $100 \%$ \\
\hline \multirow[t]{3}{*}{ Syllabus } & Syllabus is lengthy. & 06 & $60 \%$ \\
\hline & Syllabus is difficult. & 02 & $20 \%$ \\
\hline & Syllabus is ok. & 02 & $20 \%$ \\
\hline Total & & 10 & $100 \%$ \\
\hline \multirow[t]{2}{*}{ Teacher Trainings } & There are no workshops for the English teachers. & 06 & $60 \%$ \\
\hline & Lack of refresher courses. & 04 & $40 \%$ \\
\hline Total & & 10 & $100 \%$ \\
\hline Grand Total & & & $100 \%$ \\
\hline
\end{tabular}

Table 2 presents the overall findings of the problems faced by the English teachers, teaching in the multilingual classrooms of Quetta, Baluchistan, Pakistan.

\subsection{Multilingual Class}

Multilingual classroom emerged as a major theme from the data. It was reported as one of the biggest challenges 
at government girls' secondary schools by all the participants. During the classroom observations, it was also seen that the learners are from different lingual backgrounds and teachers are facing a lot of difficulties while teaching the English language. English is neither learner's first nor second but a third language here in Baluchistan context. Moreover, the learners' have no exposure to English language outside the classroom. Students who attend government schools are mostly from the poor families and cannot afford to join the English language centers. It is an enormous challenge for the English language teachers to cope with the situation, created in the class due to language diversity, as students speak different local languages at their homes such as, Pashto, Brahvi, Baluchi, Saraiki, Punjabi and Persian. In rural Baluchistan, the situation becomes even worse when the English teachers are compelled to use the mother-tongue of the students because they do not understand a single word uttered in English language. Moreover, teaching a third language is entirely different from teaching a second language and English is taught as a third language in Baluchistan. According to one of the participants:

P1. "It is very challenging for the English teacher to teach in a multilingual class due to the language diversity".

\subsection{Weak Linguistic Background}

The participants agreed on this point too that students' weak linguistic background is yet another challenge in the multilingual classrooms. All the 10 participants reported it as another major challenge. As per the respondents' views, the students cannot understand even the short sentences in English language and after several repetitions students still feel shy to use English language in their conversation. These students do not belong to educated families and English is not commonly spoken by them. Furthermore, when these students attend government schools which are already Urdu medium, they face a lot of difficulties. The themes emerged from the interviews show that the influence of many regional languages can be seen in the interaction between teachers and students in the classrooms. Moreover, the teachers and the students were found code-switching during the class from English to Urdu or other languages.

In the multilingual classrooms of Quetta, Baluchistan, teachers are bound to use the technique of code-switching in natural flow of classroom discourse. The learners cannot understand the instructions given in English language only. The class observation showed that teachers and students both were constantly code-switching in the classrooms. One of the participants exemplifies that situation:

P.6: "Students have no background in English language and they cannot understand the instructions given in English".

\subsection{Anxiety among Learners}

Anxiety factor among the learners studying in a multilingual classroom emerged as another major theme. The respondents believe that, the students who have no background in English language are more likely to act like a passive listener in the classrooms and do not take an active part in classroom discussions or activities. MacIntyre \& Gardner (1994) describe language anxiety as, the feeling of tension and apprehension specifically associated with second language contexts, including speaking, listening, and learning. The learners feel like if they would say anything wrong, their classmates or the teacher might laugh at them. Horwitz et al. (1986) mentions language anxiety as "a distinct complex of self-perceptions, beliefs, feelings, and behaviors related to classroom language learning arising from the uniqueness of the language learning process" (p. 128). These aspects of anxiety show that learners feel tense in a multilingual class where they cannot express their feelings when they are not aware of English language. To make the learning process more successful, the learners should be anxiety free. Students who belong to different lingual backgrounds have no exposure to English language and they feel hesitant to speak in English with their teachers and classmates. According to one of the participants:

P.4: "Students lack confidence and feel nervousness and hesitation while speaking English language".

\subsection{Lengthy Syllabus}

The patterns and themes emerged from the data revealed lengthy syllabus as another challenge reported by all the respondents. The government schools across Baluchistan follow the same syllabus and curriculum. Students living in Quetta city find it less difficult as compared to the students of the rural areas of Baluchistan. The respondents reported that they have a limited time to cover the syllabus and the difficulty even increases when the class is multilingual. The students do not follow the directions given by the teacher. Hence, the teachers are bound to cover the syllabus on time so they cannot repeat the lesson over and over again.

The perception of the learners is always neglected in such circumstances where the teachers are time bound. In these classrooms, the students remain quiet or least interested and hardly respond to the teachers. Furthermore, most of the respondents found vocabulary very difficult according to the mental level of the students, they added 
that, most of the lessons given in the books are not written according to the Pakistani context, there are unnecessary exercises and no creative-writing activities are added in the text books. The students are totally dependent on the teachers to do the exercises. The following response seems to prove this:

P.9: "Syllabus is lengthy and it is very difficult to complete it on time".

\subsection{Lack of Teacher Trainings}

As emerged from the themes the findings of the study revealed that government school English teachers were never given a single chance to attend any training based on English language pedagogy. All the respondents agreed to the point that they have not attended a single training or any refresher course as yet though they have been teaching English for a couple of years in their schools. Multilingual classrooms are always challenging for the teachers therefore, teachers who teach in such classes should be trained enough to cope with the difficulties.

Teachers, who are professionally trained and groomed, can handle their multilingual classrooms in much better way as compared to the teachers who are not trained. The teachers also suggested that, there should be trainings especially designed for the English language teachers so they may make the learning process in a multilingual classroom more effective and fruitful. If teacher tactfully handles the class, he/she can reduce many challenges. One of the participants' original words:

P.5: "There are no trainings or workshops for the English language teachers, government should conduct trainings".

\section{Findings of the Second Research Question}

There were some useful strategies employed by the female English teachers to overcome the challenges of a multilingual classroom.

\subsection{Teacher Trainings}

All the 10 female English teachers suggested that there should be teacher trainings especially designed for the English teachers so they may cope with the challenges of multilingual classrooms. According to the participants:

P: 2 "Our English teachers are not trained enough to teach English language in a multilingual classroom. There should be professional development courses and trainings for the English teachers".

\subsection{Syllabus Should Be According to the Needs of Learners}

The female English teachers suggested that the syllabus should be according to the needs and desires of the students. In Baluchistan, the same syllabus is being followed in all the government schools and students are tested through the same examination system. The needs of the students in rural Baluchistan are entirely different from the students of the urban areas. According to the teachers, the rural areas students find it quite difficult to understand because of the difficult vocabulary and grammar used in the English text books.

\subsection{Rewards for the Students}

The female English teachers suggested that there should be rewards for the students' motivation purpose. Those students, who try to speak English in the classroom, should be appreciated by the English teachers and the school administration. Moreover, other students may also feel motivated by this action and they also may try to speak in English language.

\section{Results of Classroom Observations}

The researcher observed the classes of all the ten participants. The results of classroom observations of the participants are quite the same as reported by the participants during the interviews.

In the classrooms, the students were constantly using their mother-tongue with their classmates for communication purposes. However; majority of the students were communicating with their English teacher in Urdu language.

Teachers were repetitively using Urdu language because students were unable to understand if the instructions were given in English language only.

At times teachers and students both were found using local languages in the classroom such as Baluchi, Brahvi, Pushto, Punjabi and Persian because the students were hesitant to communicate in English language due to anxiety factor and lack of confidence.

The duration of class was just 30 minutes which is insufficient to teach English language.

The observations generally confirmed the results from the interviews that multilingual classrooms are the biggest challenge for the English language teachers. 


\section{Discussion}

This study aimed to determine the challenges faced by the female secondary school English teachers while teaching English language in a multilingual context of Quetta, Baluchistan, Pakistan. It is an enormous challenge for the English teachers because students in this region belong to different lingual and cultural backgrounds and thus they do speak different local and regional languages such as Persian, Baluchi, Brahvi, Pashto, Punjabi and Saraiki. It is hard for a teacher to cope with the challenges at many occasions in the multilingual classrooms. Students coming to government schools do not belong to well-off families and they cannot take admissions in language centers to improve their English language skills. Furthermore, during the classroom observations it was seen that the students cannot communicate in English language and teacher is facing difficulties. The findings of the study are similar to the findings of Haukås (2016) who figured out that multilingual classrooms are always challenging and teaching a third language is entirely different from teaching a second language.

In the multilingual classrooms, teachers continuously code-switch from English to Urdu to make the students understand as Urdu is commonly understood by all the students in Quetta city. On the other hand, in rural areas of Baluchistan teachers translate for the students in their local languages too because they cannot understand even Urdu which is the national language of Pakistan. During the classroom observations, teachers were found code-switching because it works as an aid in the multilingual classrooms.

Lengthy and difficult syllabus also emerged as one of the major themes from the data. Majority of the teachers reported it as a challenge. According to the teachers they find the English syllabus lengthy, difficult and not according to the mental level of the learners. Students mostly do not understand the vocabulary and teachers are compelled to repeat the lesson over and over again. Teachers further reported that while assessing, no output is given by the students in the class tests and they never show good result in examination. The findings of the study are very much similar to the findings of Teevno (2011) who found out in one of his studies that difficult and lengthy English syllabus is yet another challenge in the multilingual classrooms.

The opted teachers reported many other challenges too such as weak linguistic background of the students, anxiety among learners and lack of teacher trainings. All the ten participants agreed to the point that government do not conduct workshops for the English language teachers and thus the teachers are compelled to make personal efforts in order to improve their pedagogical skills. The results of this study are quite similar to the study of Noom-Ura (2013) who found out that there should be trainings, workshops and refresher courses specially designed for the English language teachers.

\section{Conclusion}

The study intended to figure out the challenges faced by the female secondary school English teachers, teaching in the multilingual classrooms. The participants' views and classroom observations suggest that teaching English language in a multilingual context of Baluchistan is an enormous challenge for the English teachers. In the multilingual classrooms, teachers need to put extra efforts due to language diversity. Similarly, students need to be more focused and attentive in order to learn English language in more effective manner. Teachers are time bound in government schools and they have a limited time to complete the syllabus. Language practices in classroom boost power and intercultural issues (De Haan \& Elbers 2009). The study shows that students' weak linguistic background in English language makes it even more challenging for the teacher to cope with the situation because of continuous code-switching from English to Urdu or sometimes in the local languages of the learners. Furthermore, there are no teacher trainings for the English teachers to learn the new teaching strategies and methodologies to make the English language teaching more effective and interesting for the learners.

\section{Future Research Directions}

For the data collection of present study, only female secondary school English teachers were selected as a sample. Therefore; for the future studies, the sample of both (male \& female) participants could be selected to figure out the challenges they face while teaching English language in their multilingual classrooms. For this research, the class of each participant was observed just once. Thus; it cannot be assumed that the challenges reported by the participants during the interviews were actually the challenges. Therefore, in the future each classroom could be observed for a week or so to obtain more accurate results.

\section{References}

Abongdia, A. J., \& Foncha, W. J. (2015). Pre-service teachers' challenges during teaching Practice in one university in the Eastern Cape, South Africa. Int J Edu Sci, 11(1), 50-56

Akram, M., \& Qureshi, A. H. (2012). Problems in Learning and Teaching English Pronunciation in Pakistan. International Journal of Research in Linguistics and Lexicography. INTJR-LL-1, (4), 43-48. 
Braun, V., \& Clarke, V. (2006). Using thematic analysis in psychology. Qualitative Research in Psychology, 3(2), 77-101. http://dx.doi.org/10.1191/1478088706qp063oa

Cohen, L., Manion, L., \& Morison, K. (2007). Research Methods in Education (6th ed.). London: Routledge.

De Haan, M., \& Elbers, E. (2009). From research to practice. What the study of multiethnic classrooms has to offer. Social Interactions in Multicultural Settings, 171-202.

Dhillon, J. K., \& Wanjiru, J. (2013). Challenges and strategies for teachers and learners of English as a second language: The case of an urban primary school in Kenya. International Journal of English Linguistics, 3(2), 14. http://dx.doi.org/10.5539/ijel.v3n2p14

Gopang, B. I., Bhugio, A. F., Umrani, T., \& Lohar, A. S. (2015). English speaking anxiety: A study of undergraduates at Lasbela University, Baluchistan. International Researchers, 4(1).

Govt. of Pakistan. (2015). Economic Survey of Pakistan 1999-2000. Economic Advisor's Wing, Finance Division, Islamabad. Pakistan pp. 117, 139.

Haukås, A. (2016). Teachers' beliefs about multilingualism and a multilingual pedagogical approach. International Journal of Multilingualism, 13(1), 1-18. https://doi.org/10.1080/14790718.2015.1041960

Horwitz, E. K., Horwitz, M. B., \& Cope, J. (1986). Foreign language classroom anxiety. The Modern Language Journal, 70, 725-732. https://doi.org/10.1111/j.1540-4781.1986.tb05256.x

Ismaili, M. (2015). Teaching English in a multilingual setting. International Journal of Information Research and Review, 2(4), 646-648. https://doi.org/10.1016/j.sbspro.2015.07.505

Jiménez, R. T., \& Rose, B. C. (2010). Knowing how to know: Building meaningful relationships through instruction that meets the needs of students learning English. Journal of Teacher Education, 61(5), 403-412. https://doi.org/10.1177/0022487110375805

Khan, T. J., \& Khan, N. (2016) Obstacles in Learning English as a Second Language among Intermediate Students of Districts Mianwali and Bhakkar, Pakistan. Open Journal of Social Sciences, 4, 154-162. http://dx.doi.org/10.4236/jss.2016.42021

Lartec, J., Belisario, A. M., Bendanillo, J. P., Binas-o, H. K., Bucang, N. O., \& Cammagay, J. L. W. (2014). Strategies and problems encountered by teachers in implementing mother tongue-based instruction in a multilingual classroom. The IAFOR Journal of Language Learning, 1(1), 1-16. https://doi.org/10.22492/ijll.1.1.04

MacIntyre, P. D., \& Gardner, R. C. (1994). The subtle effects of language anxiety on cognitive processing in the $\begin{array}{llll}\text { Second language learning. Language Learning, 44(2), 283-305. } & \text {. }\end{array}$ https://doi.org/10.1111/j.1467-1770.1994.tb01103.x

Malone, S. (2007). Mother tongue-based multilingual education: Implications for education policy. Seminar on Education Policy and the Right to Education: Towards more Equitable Outcomes for South Asia's Children. Kathmandu (pp. 17-20).

Noom-Ura, S. (2013). English-teaching problems in Thailand and Thai teachers' professional development needs. English Language Teaching, 6(11), 139. https://doi.org/10.5539/elt.v6n11p139

Paik, J. (2008). Learning English, imagining global: The narratives of early English education experiences in South Korea. The International Journal of Learning, 15(10), 71-78. https://doi.org/10.18848/1447-9494/cgp/v15i10/45983

Patil, Z. N. (2008). Re-thinking the objectives of teaching English in Asia. Asian EFL Journal, 10(4), 227-240.

Teevno, R. A. (2011). Challenges in teaching and learning of English at Secondary Level Class X. International Journal of Human Resource Studies, 1(2), 27. https://doi.org/10.5296/ijhrs.v1i2.1029

Tufail, R., Kanwal, A., \& BadarToor, S. (2015). Urdu Speaking EFL Students Problems in Learning English in Public and Private Schools of Punjab, Pakistan. Bulletin of Business and Economics (BBE), 4(1), 43-47.

Zeeshan, M. (2013). Pakistani government secondary school teachers' and students' attitude towards communicative language teaching and grammar translation in Quetta, Balochistan (Doctoral dissertation, CALIFORNIA STATE UNIVERSITY, LOS ANGELES). 


\section{Appendix A}

\section{Semi Structured Interview Protocol}

Teaching and Learning English Language in a Multilingual Setting

\section{Background information of the teachers.}

1. What is your mother-tongue?

2. How did you learn English language?

3. Please tell me that how long have you been teaching English?

4. What is your qualification?

5. Which grade do you teach?

6. What is the strength of your class?

7. What is the mother-tongue (L1) of your students?

8. What is the language of instructions in your class?

10. How do you teach English language?

11. What is the level of students' understanding when the instructions are given only in English language?

12. What problems do you face as an English language teacher?

13. Please suggest the strategies you employ to overcome these problems.

\section{Appendix B}

\section{Observational Checklist}

The purpose of the observation is to compare participants' challenges they face in their multilingual classrooms.

\section{Section A}

Teacher's Name Date

Class Observed Time

Observer's Name Number of Students

\section{Section B}

\section{Challenges faced by the female secondary school teachers in their multilingual classrooms}

1. Teachers' use of mother-tongue in the classroom.

2. Language used by the students for communication purpose.

3. Use of English language by the teacher.

4. Use of English language by the students.

5. Reaction of the students if the instructions are given in English language only.

6. Language of instruction by the teacher.

7. Motivational strategies to speak in English language used by the teacher.

\section{Comments:}

\section{Copyrights}

Copyright for this article is retained by the author(s), with first publication rights granted to the journal.

This is an open-access article distributed under the terms and conditions of the Creative Commons Attribution license (http://creativecommons.org/licenses/by/4.0/). 